\title{
Fourteen Years' Survival After Batista Operation: The Short History of a Long Journey
}

\author{
Gustavo Luiz Gouvêa de Almeida Junior, ${ }^{\circledR}$ Waldir Jazbik, ${ }^{3}$ Juliana Visconti Morgado, ${ }^{4,5}$ Gustavo Luiz Gouvêa de \\ Almeida ${ }^{20}$ \\ Casa de Saúde São José,' Rio de Janeiro, RJ - Brazil \\ Santa Casa da Misericordia do Rio de Janeiro, ${ }^{2}$ Rio de Janeiro, RJ - Brazil \\ Hospital Universitário Pedro Ernesto, Universidade Estadual do Rio de Janeiro (UERJ), ${ }^{3}$ Rio de Janeiro, $R J$ - Brazil \\ Hospital Israelita Albert Sabin, ${ }^{4}$ Rio de Janeiro, RJ - Brazil \\ Hospital Casa Prontocor, ${ }^{5}$ Rio de Janeiro, $R J$ - Brazil
}

\section{Abstract}

A 41-year-old man with end-stage heart failure due to nonischemic dilated cardiomyopathy was submitted to the Batista procedure as an alternative to heart transplantation. With surgery, the patient showed progressive clinical amelioration, achieving long-term stable NYHA functional class II, despite gradual dilation of the heart chambers. Persistent atrial fibrillation appeared on the last year of life, his clinical condition deteriorated, and the patient died 14 years, four months, and 13 days after the operation. To the best of our knowledge this seems to be the longest reported survival for a patient submitted to Batista operation.

\section{Introduction}

Heart failure (HF) is one of most severe diseases affecting man, showing high morbidity and mortality. Once HF is diagnosed, survival is around 50\% and 10\% at 5 and 10 years, respectively. One of the main causes of heart failure is dilated cardiomyopathy (DCM), which is one of the main indications for heart transplant (HT). Historically, however, the potential benefits of HT have been very limited due to shortage of suitable donors, several contraindications, high financial costs and mortality due to infection, neoplasms, allograft rejection

\section{Keywords}

Heart Failure/physiopathology; Partial Left ventriculectomy; Cardiac Surgery; Ventricular Dysfunction, Left/surgery; Cardiomyopathy, Dilated/surgery. and other complications..$^{1-2}$ Meanwhile, a considerable proportion of patients die annually while on the waiting list and only a small proportion of candidates can benefit from a new heart. ${ }^{1-2}$

To overcome such limitations, in the mid-1990s, the Brazilian surgeon Randas Batista and coworkers created an innovative and radical operation, named partial left ventriculectomy (also referred to as PLV, Batista operation and Batista procedure) to treat patients with end-stage heart failure as an alternative to HT. ${ }^{3}$ By using an original concept based on Laplace's law, where ventricular wall stress $=$ intracavity pressure $\mathrm{x}$ radius $/ 2 \mathrm{x}$ wall thickness, the rationale for the procedure was that, by reducing the dilated ventricular cavity, a normalization of chamber volume/mass ratio could be re-established. Then, they postulated that a decrease in tension on the left ventricular wall through volume reduction could decrease wall stress and myocardial consumption of oxygen, resulting in systolic function improvement.

The initial results obtained with the PLV generated tremendous enthusiasm among surgeons worldwide and more than 70 centers, at least 20 in Japan, performed the surgery in the 1990's. At that time, several centers in Brazil adopted the surgery and the I Brazilian Guidelines for Cardiac Transplantation recognized PLV as an alternative to HT. ${ }^{1}$ However, the prestige of PLV began to decline at 2001's when a report from the Cleveland Clinic Foundation demonstrated perioperative failures that could preclude its widespread use. ${ }^{4}$ At the same time, however, this study emphasized that, due to its possible beneficial effects, the Batista surgery could be employed in situations that do not allow a transplant or as a biological bridge to a new heart. Meanwhile in Japan, ventricular restoration surgery, including more a refined 
Batista procedure, remains alive and has been considered a good non-transplant option for selected patients with end-stage DCM. Curiously, in relation to United States, the Batista procedure was not completely discontinued, considering that in the period of 2008-2014 it was applied in 401 patients but has been decreasing over time and is now employed in a limited number of selected patients. ${ }^{5}$

Few cases of very long-term survival with PLV have been reported in the medical literature to date, in which patients were clinically well at the time of the publication and the longest reported survival is a 68 -year-old woman who was alive 13 years after the operation that, coincidentally, was the first PLV applied in Korea. ${ }^{6}$

\section{Clinical case}

A 41-year-old man with a six-month history of progressive HF due to nonischemic DCM was hospitalized for clinical treatment, receiving bed rest, fluid restriction, diuretics, cardiac glycoside, ACE inhibitor (ACEI) (captopril), heparin and pentoxifylline, with transient improvement. He had no history of diabetes, hypertension, angina and myocardial infarction. His coronary angiography was normal and serologic testing for Chagas disease, cytomegalovirus, hepatitis virus $\mathrm{A}, \mathrm{B}, \mathrm{C}, \mathrm{E}$ and $\mathrm{HIV}$ infection all were negative. Despite treatment optimization, his clinical condition rapidly deteriorated and end-stage heart failure was diagnosed, necessitating inotropic therapy with dobutamine. The patient was listed for cardiac transplant. However, the heart of the problem was that, due to the shortage of organs and serious logistic difficulties at that time, the Batista surgery was offered as the last effort to save his life. An informed consent was obtained from the patient for the surgery.

The procedure was carried out in August 1998. The operation was performed under normothermic standard cardiopulmonary bypass and the technique used was based on that originally described by Batista and colleagues. ${ }^{3}$ In simple terms, the procedure consisted of resection of a large slice of the posterolateral LV wall, beginning from the apex to near the mitral annulus, preserving the papillary muscles and subsequent ventriculorraphy. It is interesting to note that right ventriculectomy was also performed at the same time, because of the large right ventricular dilatation. Concomitant mitral and tricuspid repairs were performed. The postoperative course was uneventful.
Pre-and postoperative transthoracic echocardiography data are summarized in Table 1. One month after the operation, the echocardiographic examination showed significant improvement: the left atrial and ventricular sizes as well as right ventricular dimensions were reduced, LV ejection fraction increased, while pulmonary arterial systolic pressure declined. Trivial tricuspid and mitral regurgitation remained after surgery. The patient achieved NYHA class-II, remaining under optimized medication with furosemide, ACEI, spironolactone, B-blocker (carvedilol) and digoxin. The nutrition was improved, and the patient gradually recovered his normal weight.

Although at six months after the procedure the heart chambers were redilated, the patient still continued to maintain good clinical condition. Thirteen years after the operation the transthoracic echocardiogram and the cardiac MRI showed enlargement of the heart chambers, atrioventricular valve regurgitation and severe ventricular systolic dysfunction (Figures 1-A, 1-B, 2-A and 2-B). The clinical condition deteriorated only in the last year of his life, after the development of persistent atrial fibrillation, requiring several hospitalizations.

\section{Discussion}

Despite modern treatment of patients with advanced DCM, the morbi-mortality rates continue to be high and

Table 1 - Pre-and postoperative echocardiographic data

\begin{tabular}{lcccc}
\hline & \multicolumn{5}{c}{ Postop } \\
\hline Variable & Preop & 1 month & 6 months & 13 years \\
\hline LA (cm) & 5.7 & 4.1 & 6.0 & 6.4 \\
LVSD (cm) & 6.9 & 4.9 & 5.9 & 6.8 \\
LVDD (cm) & 7.4 & 5.9 & 6.5 & 7.4 \\
SV (ml) & 42 & 60 & 43 & 40 \\
RVD (cm) & 3.5 & 2.7 & 3.3 & 3.7 \\
LVEF (\%) & 14 & 35 & 20 & 17 \\
PASP & 50 & 37 & 65 & 59 \\
$(\mathrm{mmHg})$ & & & &
\end{tabular}

LA: left atrium; LVSD: left ventricular systolic diameter; LVDD: left ventricular diastolic diameter; SV: systolic volume; RVD: right ventricular diameter; LVEF: left ventricular ejection fraction; PASP: pulmonary artery systolic pressure. 

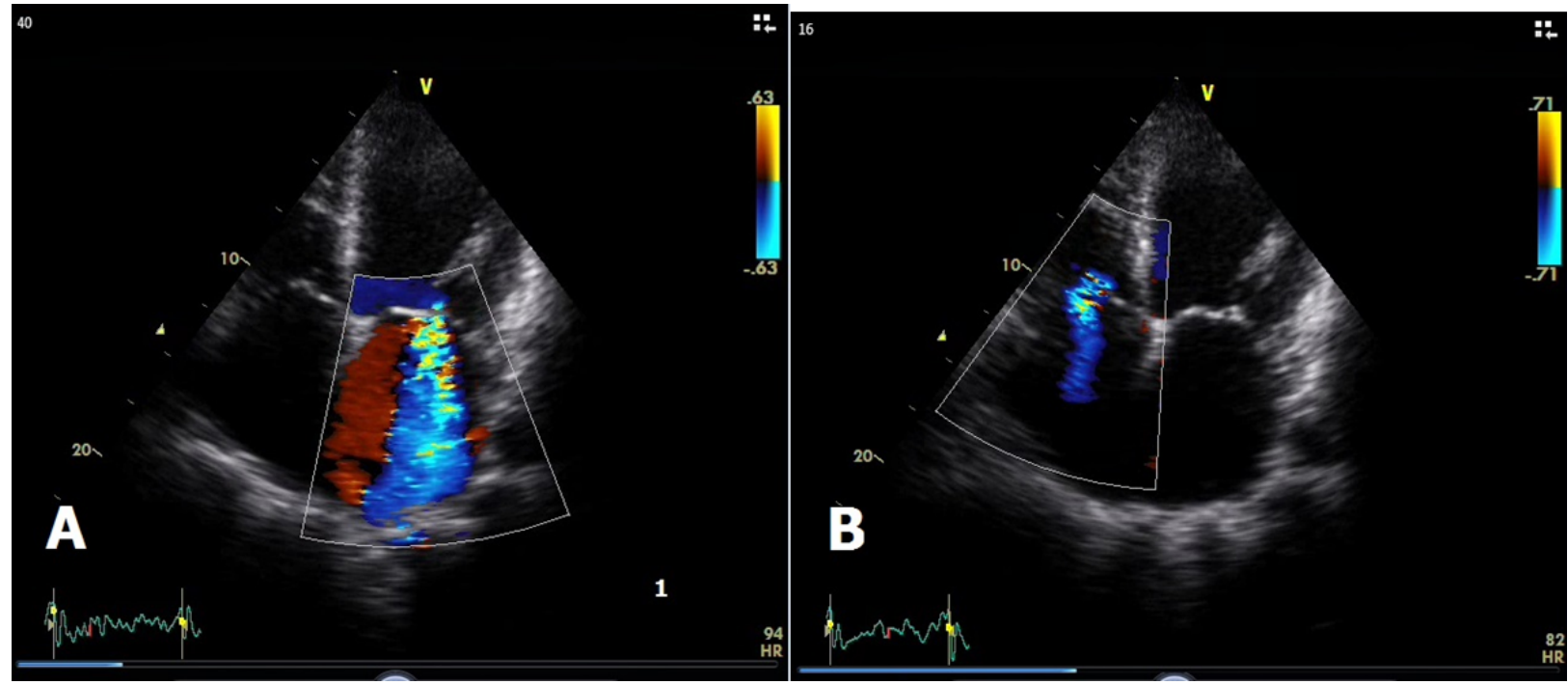

Figure 1 - Transthoracic echocardiogram showing dilated chambers, severe mitral regurgitation (A) and mild tricuspid incompetence (B).

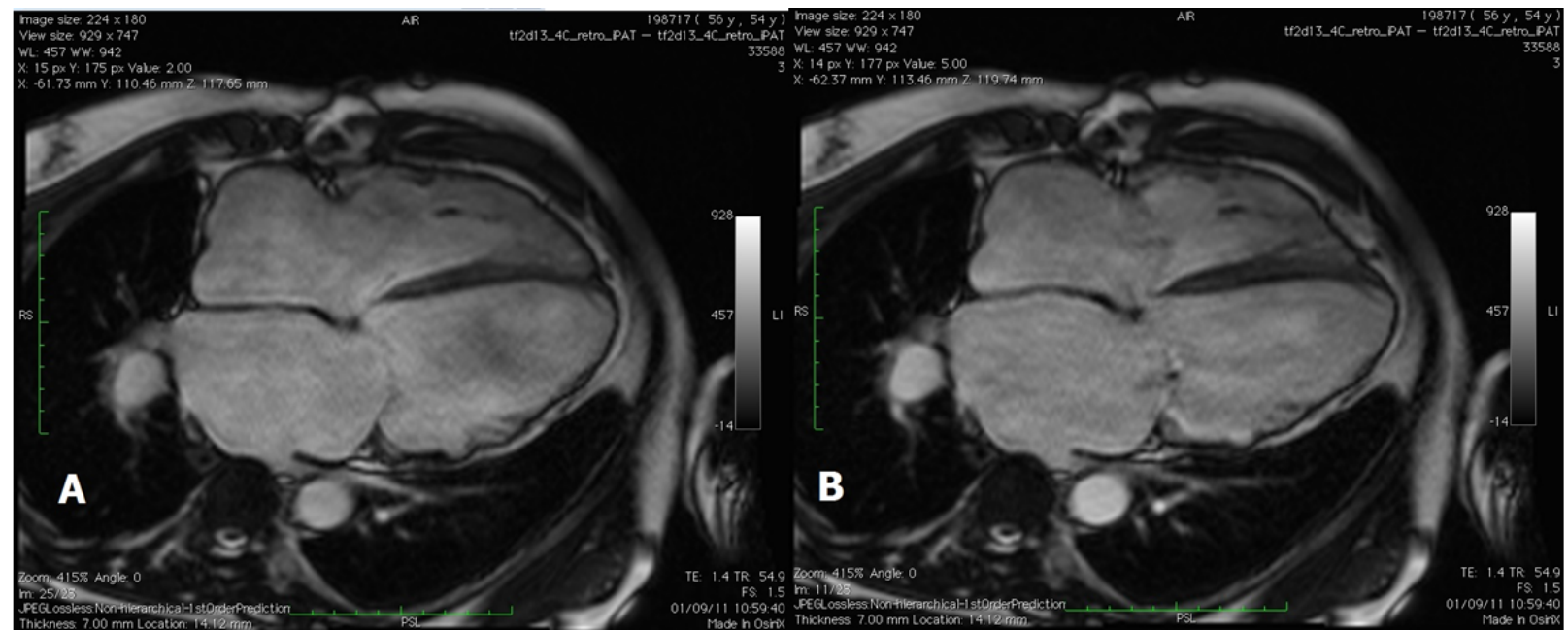

Figure 2 - Cardiac MRI: long axis views at diastole (A) and systole (B), showing dilated heart chambers, wall thinning and severe ventricular systolic dysfunction.

patients with poor responses to medical therapy may need surgical options, including HT and mechanical circulatory support. Non-transplant cardiac strategy for treatment of advanced DCM, such as the Batista procedure, has been applied to hundreds of people worldwide as an alternative or as bridge to HT.

Although the procedure were drastically reduced after 2001 in most countries, it is significant that, since 
PLV creation, several recent reports about its success rates have appeared, revealing a renewed interest on the subject. ${ }^{5,7-10}$

Patients with advanced DCM under clinical therapy may have poor quality of life and unfavorable longterm prognosis, with or without ventricular volume reduction surgery, but it is also significant that many patients submitted to Batista procedure has lived for months or years, with much better clinical status and cardiac function than before. In our opinion, PLV can still be performed in selected patients with advanced heart failure, refractory to pharmacological therapy, when heart transplant is not available.

It is important to note that patients submitted to PLV were compared in the literature with patients undergoing heart transplantation. There is no direct comparison of PLV with optimized clinical treatment, since the optimized clinical treatment failure is necessary for surgery indication. Only patients who remain very symptomatic with optimized clinical treatment or those who are inotropic-dependent have been indicated for treatment with PLV as an alternative to cardiac transplantation. In our patient, clinical treatment optimization was attempted to the maximum extent possible, but he remained refractory and dependent on inotropes, in what is now classified as INTERMACS 3.

In our patient, the subsequent cardiac chamber redilation, the progression of mitral regurgitation over time and the decrease in ventricular function were all potential significant adverse factors for a favorable longterm outcome. However, it is extraordinary that, despite such limitations, he lived for 14 years, four months and 13 days after the operation. Possible explanations for the long-term survival would be the optimization of pharmacological therapy (he did not tolerate the use of beta-blockers and only reduced doses of ACEI were used before the surgery), as well as nutritional adjustment in the postoperative period (his weight at the time of surgery was $39 \mathrm{~kg}$ and after 1 year he reached $67 \mathrm{~kg}$, compensated). In addition, the right ventriculectomy and the correction of the mitral-tricuspid regurgitation were factors that probably contributed to a favorable outcome.

\section{Conclusion}

This is a rare case of long-term survival of a patient with advanced heart failure, who was submitted to partial left ventriculectomy. Since the patient did not tolerate optimized clinical therapy, necessitating inotropic support, partial biventriculectomy and concomitant mitral and tricuspid repair were applied, resulting in a favorable outcome, allowing the patient to present excellent clinical recovery and an exceptional long-term survival.

\section{Acknowledgment}

To Cantídio Drumond Neto, in memoriam. Chief of Cardiology (6a Enf.) of Santa Casa da Misericórdia do Rio de Janeiro. Thank you for the support during the years when we cared for the patient described in the present report, for your friendship and for being a true master. His still strong presence continues to stimulate us to grow scientifically.

\section{Author contributions}

Conception and design of the research: Almeida Junior GLG, Jazbik W, Morgado JV, Almeida GLG. Acquisition of data: Almeida Junior GLG, Jazbik W, Morgado JV. Analysis and interpretation of the data: Almeida Junior GLG, Morgado JV, Almeida GLG. Writing of the manuscript: Almeida Junior GLG, Almeida GLG. Critical revision of the manuscript for intellectual content: Almeida Junior GLG, Morgado JV, Almeida GLG.

\section{Potential Conflict of Interest}

No potential conflict of interest relevant to this article was reported.

\section{Sources of Funding}

There were no external funding sources for this study.

\section{Study Association}

This study is not associated with any thesis or dissertation work.

\section{Ethics approval and consent to participate}

This article does not contain any studies with human participants or animals performed by any of the authors. 


\section{References}

1. Bocchi EA, Fiorelli A, Moreira LF, Bacal F; Sociedade Brasileira de Cardiologia. I Diretriz da Sociedade Brasileira de Cardiologia para Transplante Cardíaco. Arq Bras Cardiol. 1999;73( supl 5):1-56.

2. Gradinac S, Popović Z, Mirić M, Vasiljević J, Nastasić S, Perić M, et al. Partial left ventriculectomy and limited heart transplantation availability. J Card Surg. 2001;16(2):165-9.

3. Batista RJV, Santos JLV, Franzoni M, Araújo ACF, Takeshita N, Furukava M. et al. Ventriculectomia parcial: um novo conceito no tratamento cirúrgico de cardiopatias em fase final. Rev Bras Cir Cardiovasc. 1996;11(1):1-6.

4. Franco-Cereceda A, McCarthy PM, Blackstone EH, Hoercher KJ, White JA, Young JB, et al. Partial left ventriculectomy for dilated cardiomyopathy: is this an alternative to transplantation? J Thorac Cardiovasc Surg. 2001;121(5):879-93.

5. Roy SD, Taduru SS, Taneja A, Ramakrishnan D, Omer MA, Baweja P. Recent trends in surgical management of heart failure in the united states. J Card Fail. 2017;23(8):S122.
6. Shin MS, Ahn TH, Kim OR, Chung WJ, Kang WC, Lee KH, et al. Realtime 3-dimensional echocardiography of the heart 13 years after partial left ventriculectomy. Korean Circ J. 2010;40(6):295-8.

7. Domingues JS, Vale MP, Barbosa MP. Partial left ventriculectomy: have well-succeeded cases and innovations in the procedure been observed in the last 12 years? Braz J Cardiovasc Surg. 2015; 30(5):579-85.

8. Sugiyama H, Hashioki M, Naitoh A, Kadono T, Suzuki S, Sugita K. Outcome of non-transplant surgical strategy for end-stage dilated cardiomyopathy in young children. Circ J. 2009;73(6):1045-8.

9. Suma H. Partial left ventriculectomy. Circ J. 2009;73(Suppl A):A19-22.

10. Morimoto K, Kuroda H., Ono K, Miyasaka S, Shiraya S, Kobayashi F. et al. Modified Batista procedure for idiopathic dilated cardiomyopathy: report of a case. World J Cardiovasc Surg. 2017;7: 32-40. 